\title{
The Burdens of Family Caregivers of Schizophrenia in Mauritius
}

\author{
Nilmala Devi Aubeeluck ${ }^{a}$, Amitabye Luximon-Ramma ${ }^{{ }^{*}}$ \\ ${ }^{a}$ School of Health Sciences, University of Technology, Mauritius, La Tour Koenig, Pointe aux Sables, Mauritius.
}

Received 27 April 2020; Accepted 12 July 2020

\begin{abstract}
Introduction: Schizophrenia is a severe mental illness impacting not only on the lives of patients but also on their family members. No studies were conducted on family caregivers of patients with schizophrenia in Mauritius. Objectives: The aim of the study was to identify the impact of caregiving on the emotional, physical, social health and financial situations of family caregivers in Mauritius. Method: The study was conducted with 144 family caregivers of schizophrenia patients from the Brown Sequard Mental Health Care Centre. The caregivers were surveyed through a validated questionnaire and the data were analysed using the SPSS, Version 23. Results: Majority of the carers were female (65.3\%), most were above 55 years and married $(73.6 \%)$ and $46.5 \%$ studied up to secondary level. $89 \%$ did not have any informal training about caregiving and most were unaware of the name of the illness. The caregiver's emotion, physical, social and financial health was positively correlated with age having Pearson Correlation values of $0.218,0.205,0.216$ and 0.192 respectively and p-values $0.009,0.014,0.00$ and 0.021 respectively. A significant number of the respondent $(82 \%)$ always worried about their own safety when the patient became violent, and most of them avoidedlarge social events with their relatives. Moreover, majority of the caregivers (62.5\%), mostly the females, complained of facing financial difficulties and were dissatisfied with the Social services received during the last 12 months. Conclusion: It may be concluded that an increase in care-giving role resulted in poor emotional well-being, poor physical and social health and an increase in financial worry. This study provides an insight that may help health professionals to plan and develop better health management programs to improve the quality of life and reduce burden of family caregivers of schizophrenia patients in Mauritius.
\end{abstract}

Keywords: Schizophrenia; Family Caregiver; Emotional Wellbeing; Physical Health; Social Health; Financial Worry; Knowledge.

\section{Introduction}

Schizophrenia is one of the top 15 leading causes of disability worldwide [1] with patients experiencing deficits in a variety of everyday functional domains [2] of independence in residence, productive activities, and social interactions [3]. It is among the most burdensome and costly illnesses worldwide [4]. In schizophrenia, the most poignant and well characterized determinants of disability are symptoms, cognitive and related skills deficits, but there is limited understanding of other relevant factors that contribute to disability.

People with schizophrenia have a long duration of illness and a limited ability to perform daily activities, impairments in social function due to several psychotic symptoms including hallucination, delusions, disorganized speech and behaviors, and negative symptoms [5], which are unpredictable, frightening, and disturbing behaviors that affect family caregivers. In addition, the impairments due to the disease of schizophrenia lead to dysfunctional or disabling symptoms that reoccur during the course of illness [6]. These impairments severely impact quality of life, and predict relapse, poor illness course, and unemployment. These disabilities are a huge burden on both patients and their caregivers. Evidence suggests that family members experience significant stress in coping with a person with schizophrenia [7].

\section{* Corresponding author: aramma@umail.utm.ac.mu

$>$ This is an open access article under the CC-BY license (https://creativecommons.org/licenses/by/4.0/).

(C) Authors retain all copyrights. 
Mauritius is a Small Island Developing State (SIDS) with 1.27 million inhabitants of diverse cultural backgrounds. In 2016, 4681 patients were admitted to the mental health centre, of whom $1800(38.5 \%)$ were admitted for alcoholrelated psychiatric conditions, 1149 (24.5\%) for schizophrenia, and $345(7.4 \%)$ for depressive disorders; the remaining patients were admitted for bipolar disorder, conduct disorders, and opioid and psychoactive substance abuse. The Brown Sequard Mental Health Care Centre (BSMHCC) is the main mental health hospital in Mauritius providing services for mental health problems. The psychiatric unit has a total of (7) psychiatrists, 45 trained nurses in psychiatric nursing and the remaining staffs are general nurses with no specialization in psychiatry. There are about 850 inpatients mostly diagnosed with schizophrenia. As in several countries, mental health is heavily stigmatised in the Mauritian society, which is a substantial barrier that prevents people from seeking appropriate treatment [8].

With the advent of deinstitutionalization in the advance world, family caregivers have increasingly assumed greater responsibility for the care of their mentally ill relatives. In Mauritius, family members equally play a major role in the care of their mentally ill relatives but unfortunately community mental health services are nonexistence. According to Park et al. [9], the caregiver is usually a relative of the ill patient and the care giving is invariably indefinite. The patient's relatives experience feelings of loss and grief [10]. They are confronted with uncertainty and emotions of shame, guilt and anger. Together with the patient, they feel stigmatized and socially isolated [11]. Addition of the caregiving role to the already existing family role may become stressful, both psychologically and economically [12]. As caregivers struggle to balance occupation, family, and caregiving, their own physical and emotional health is often ignored. In conjunction with the lack of personnel, financial and emotional resources, many caregivers often experience tremendous stress, depression, and/or anxiety in the years after care giving begins [13]. The government is entrusting the long-term care of patient with schizophrenia to family members. The question asked by Lippi [14] remains "How much knowledge family members have about the disorder and its management? In this context, studying the impact of caregiving on these family members therefore becomes especially relevant. Mauritius has not followed the same steps as the developed countries that have done extensive research on this topic. Hence, there is a vital need to carry out the study to identify the problems encountered by primary care giver and to formulate recommendations on the required interventions.

The aim of the study was to explore the family member perspective about how caregiving to member with schizophrenia affects their emotional, physical and social health and financial situations in the Mauritian context. The study is expected to bring out insight about how caregivers encounter several problems with schizophrenic patients and how they experience high levels of burden, social isolation, impaired physical health and financial difficulties. An understanding of the multiple problems encountered by family members of Schizophrenia may help to identify areas of priorities that can be incorporated into psychosocial intervention programs which can complement the efforts of mental health agencies, providers, policymakers, educators, and others in alleviating the burden.

\section{Research Methodology}

\subsection{Study Design and Setting.}

The study was conducted with family caregivers of patients with schizophrenia who visited outpatient department of Brown Sequard Mental Health Care Centre (BSMHCC) in Mauritius in early 2019. BSMHCC is the only psychiatric hospital in Mauritius. The hospital provides specialised psychiatric care to patients in form of psychotherapeutic, rehabilitative and physical intervention in collaboration with the patients, their families, friends and relatives.

\subsection{Sample and Sampling}

There are about 850 inpatients mostly diagnosed with schizophrenia. The population size of family caregivers was 300 . The sample size as determined by the Raosoft online calculator was 169 . However, only $85 \%$ family caregivers (50 males and 94 females) responded to the survey. Twenty respondents refused to take part in the survey while five respondents wrongly filled the questionnaires. The inclusion criteria were: (i) Aged 18 years or above; (ii) currently engaged in care giving of a relative diagnosed with schizophrenia, according to the DSM5 (Diagnostic and Statistical Manual of Mental Disorders); (iii) the caregiver should be a family member, or the primary carer, of the person with schizophrenia and (iv) inhabit the same house as the patient while the exclusion criteria were: (i) less than 18 years of age; (ii) having a current history of psychiatric illness; (iii) unwillingness to participate in the study. With the consent of the medical superintendent, each caregiver was approached during an outpatient clinic visit. After the study was described, each caregiver was invited to sign an informed consent form.

\subsection{Instrument}

Quantitative method was used where the data collection was done though a questionnaire comprising of 53 questions. A pilot study was conducted with ten respondents who were relatives of psychiatric outpatients attending BSMHCC. All data collection took place on-site at BSMHCC where a consultation room was provided. Approval to 
distribute questionnaire and interviewing caregivers of schizophrenic patient was obtained from the Medical Superintendent. All participants gave written informed consent.

\subsection{Validity and Reliability}

The face validity about the content of the questionnaire was verified during the pilot test via respondents' feedback. In this research, Cronbach's alpha was used as an indicator to measure the reliability.

\subsection{Statistical Analysis}

Data was analysed using the Statistical Package for Social Sciences version 23 (SPSS 23) and the Microsoft Excel 2010. The analysis was based on the total number of respondents. For scales and questions with defined categories, frequencies and percentages were calculated for each of the dimensions. The frequency values for demographics such as age, gender, income, ethnicity and caregiving duration were calculated. Correlation statistics was calculated for emotional health, physical health, general health, caregiving duration, and in the sample to determine the presence or absence of any statistically significant relationships that affects quality of life of family caregivers of persons with schizophrenia. Pearson correlation was used to measure how well two variables were related and to show their linear relationship. Pearson correlation was also used for testing significance of relationships between two variables. Inferential analysis, one sample t-test, multiple regression analysis and chi square were also used.

\section{Analysis and Findings}

Out of the 169 which were disseminated randomly at the outpatient department of BSMHCC, a response rate of $85 \%$ was obtained. The Cronbach's Alpha value of the overall data was 0.752 , hence showing reliability in the statistics.

\subsection{Demographics of Family Caregivers'}

The demographic profile is summarized in Table 1. Out of the 144 respondents, $65.3 \%$ were female and $34.7 \%$ were male. The age distribution was highest for respondents over 55 years $(28.5 \%)$ and lowest in the age group of 18 24 years old (6.3\%). Majority of the respondent were married $(73.6 \%)$ and $9 \%$ were either unmarried or widowed. As for the literacy rate of the caregivers, $46.5 \%$ studied up to secondary level, $34 \%$ up to primary level while $18 \%$ have never attended school. As profession, it was found that $34 \%$ respondents were unemployed, followed by $25.7 \%$ working in the public sector while $22.9 \%$ were employed in the private sector. Among the employed caregivers, 45.1 $\%$ received a salary in the range of MUR 10,000 - 20,000 and only 4.9\% received a salary greater than MUR 40,000. Moreover, geographically, the caregivers were equally distributed in the urban region (51.4\%) and in rural areas as shown in Table 1.

Table 1. Socio-demographic of family caregiver

\begin{tabular}{|c|c|c|c|c|c|c|c|}
\hline \multicolumn{2}{|c|}{ Characteristics } & \multirow{3}{*}{$\begin{array}{c}\mathbf{N} \\
50 \\
94\end{array}$} & \multirow{3}{*}{$\begin{array}{c}\% \\
34.7 \\
65.3\end{array}$} & \multicolumn{2}{|c|}{ Characteristics } & \multirow{2}{*}{$\begin{array}{c}\mathbf{N} \\
70\end{array}$} & \multirow{2}{*}{$\begin{array}{r}\% \\
48.6\end{array}$} \\
\hline Gender & Male & & & Pesidence & Rural & & \\
\hline 与ond & Female & & & & Urban & 74 & 51.4 \\
\hline \multirow{5}{*}{ Age Group } & $18-24$ & 9 & 6.3 & \multirow{5}{*}{ Occupation } & Public sector & 37 & 25.7 \\
\hline & $25-34$ & 26 & 18.1 & & Private sector & 33 & 22.9 \\
\hline & $35-44$ & 37 & 25.7 & & Self Employed & 14 & 9.7 \\
\hline & $45-54$ & 31 & 21.5 & & Unemployed & 49 & 34.0 \\
\hline & $>55$ & 41 & 28.5 & & Retired & 11 & 7.6 \\
\hline \multirow{5}{*}{ Marital status } & Married & 106 & 73.6 & \multirow{5}{*}{$\begin{array}{l}\text { Monthly household } \\
\text { income }\end{array}$} & < MUR 10000 & 33 & 22.9 \\
\hline & Not married & 13 & 9.0 & & MUR 10000 - 20000 & 65 & 45.1 \\
\hline & Separated & 5 & 3.5 & & MUR 21000 - 30000 & 30 & 20.8 \\
\hline & Widowed & 13 & 9.0 & & MUR 31000 - 40000 & 9 & 6.3 \\
\hline & Divorced & 7 & 4.9 & & >MUR 40000 & 7 & 4.9 \\
\hline \multirow{4}{*}{ Education } & Never been to school & 18 & 12.5 & & & & \\
\hline & Primary & 49 & 34.0 & & & & \\
\hline & Secondary & 67 & 46.5 & & & & \\
\hline & Tertiary & 10 & 6.9 & & & & \\
\hline
\end{tabular}




\subsection{Demographics of Family Care Receiver}

The demographic profile has been analysed using descriptive statistics and recorded in Table 2. 69.4\% were female and $30.6 \%$ were male. The majority of care receivers were above 60 years old $(33.3 \%)$ followed by $28.5 \%$ in the range of 50-59 years. Only $4.2 \%$ were in the age group 18-29 years of age. As for the years of illness, 38.2\% were diagnosed for the illness for more than 16 years followed by $22.9 \%$ who had the illness since $6-10$ years and $23.7 \%$ were recently diagnosed $(<5$ years $)$.

Regarding their marital status, the majority of the care receivers were unmarried (39.6\%), while $19.4 \%$ were divorced, $4.2 \%$ were separated and $1.4 \%$ was widowed. As for their level of education, the majority (61.8\%) studied up to the primary level, $19.4 \%$ never attended school, $17.4 \%$ attended completed secondary education and only $1.4 \%$ went to a tertiary institution. As for their professions, $92.4 \%$ were unemployed while only $7.6 \%$ were employed. From the analysis it can be observed that $72.9 \%$ were close relatives including mother, wife, daughter, husband, father, son and brother while $27.1 \%$ were aunt, uncle or partner.

Table 2. Demographics of family care receiver

\begin{tabular}{|c|c|c|c|c|c|}
\hline Characteristics & $\mathbf{N}$ & $\%$ & Characteristics & $\mathbf{N}$ & $\%$ \\
\hline Gender: & & & Occupation & & \\
\hline Male & 44 & 30.6 & Unemployed & 133 & 92.4 \\
\hline Female & 100 & 69.4 & Employed & 11 & 7.6 \\
\hline Age of care receiver & & & Marital status & & \\
\hline $18-29$ years & 6 & 4.2 & Unmarried & 57 & 39.6 \\
\hline 30-39 years & 27 & 18.8 & Married & 51 & 35.4 \\
\hline $40-49$ years & 22 & 15.3 & Separated & 6 & 4.2 \\
\hline 50- 59 years & 41 & 28.5 & Divorced & 28 & 19.4 \\
\hline$>60$ years & 48 & 33.3 & Widowed & 2 & 1.4 \\
\hline \multicolumn{6}{|l|}{ Education } \\
\hline Never been to school & 28 & 19.4 & & & \\
\hline Primary & 89 & 61.8 & & & \\
\hline Secondary & 25 & 17.4 & & & \\
\hline Tertiary & 2 & 1.4 & & & \\
\hline Duration of illness & & & Relationship with Caregiver & & \\
\hline 1 year & 12 & 8.3 & Wife & 19 & 13.2 \\
\hline $2-5$ years & 22 & 15.3 & Mother & 27 & 18.8 \\
\hline $6-10$ years & 33 & 22.9 & Daughter & 7 & 4.9 \\
\hline $11-15$ years & 22 & 15.3 & Husband & 12 & 8.3 \\
\hline \multirow[t]{5}{*}{$>16$ years } & 55 & 38.2 & Father & 5 & 3.5 \\
\hline & & & Son & 18 & 12.5 \\
\hline & & & Brother & 4 & 2.8 \\
\hline & & & Sister & 13 & 9.0 \\
\hline & & & Aunt/Uncle/Partner & 39 & 27.1 \\
\hline
\end{tabular}

\subsection{Time Spent by the Carers}

As per Table 3 and Figure 1 below, it can be found that the majority have more than 4 members living in the house with a total of $70.1 \%(31.9 \%+38.2 \%)$ of the respondent. $29.9 \%$ were providing care for $6-10$ years while a total of $45.8 \%(18.8 \%+27 \%)$ were giving care for more than 10 years. Moreover, more than half of the population surveyed (59\%) were giving care for more than 40 hours per week which compelled them to give up vacations, hobbies, or their own social activities.

Table 3. The time spent by the caregiver

\begin{tabular}{lc}
\hline Variable & Percentage (\%) \\
\hline Family member living in the house & \\
\hline 1 & 1.4 \\
2 & 9.0 \\
3 & 19.4 \\
4 & 31.9 \\
$>5$ & 38.2 \\
\hline
\end{tabular}




\begin{tabular}{lc}
\hline How long have you been providing care for your family member? & \\
\hline 1-5 years & 24.3 \\
6-10 years & 29.9 \\
11-20 years & 18.8 \\
> 21 years & 27 \\
\hline How much time do you spend each week helping your family member? & \\
\hline 5 hours per week or less & 3.5 \\
6 to 20 hours per week & 17.4 \\
21 to 39 hours per week & 20.1 \\
$>$ 40 hours per week & 59.0 \\
\hline Do you have to give up vacations, hobbies, or your own social activities? & \\
\hline No & 25.7 \\
Yes & 74.3 \\
\hline
\end{tabular}

In the study it was observed (Figure 1) that female caregivers spent more time per week helping the patients with schizophrenia than the male. For instance, $65 \%$ female compared to $35 \%$ male spent more than 40 hours per week in caregiving, 59\% female spent 21 hours to 40 hours per week, $72 \%$ female spent 6 to 20 hours per week and $80 \%$ female compared to $20 \%$ male spent 5 hours or less in care giving.

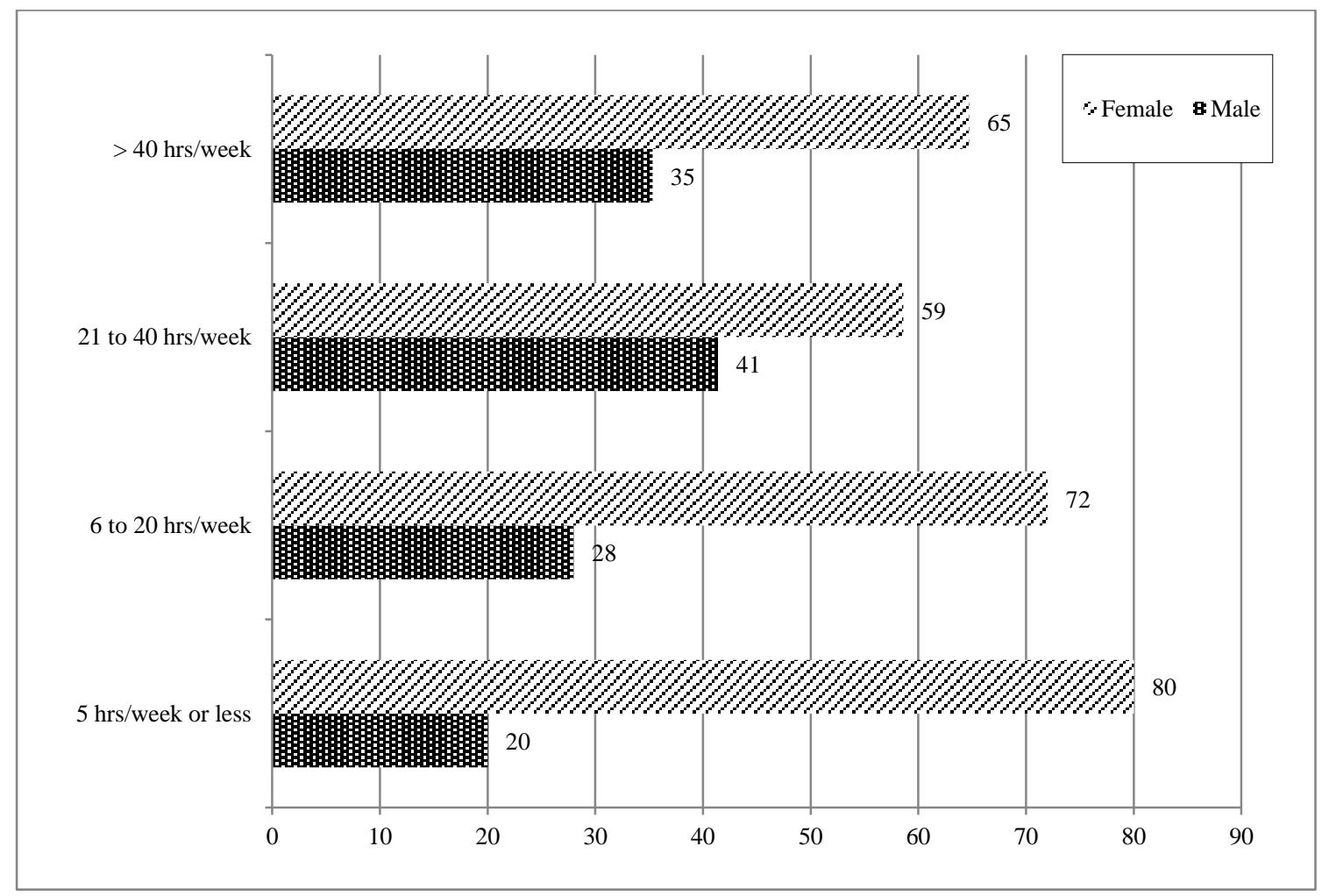

Figure 1. Time spent by gender in caregiving per week

\subsection{Carer's Awareness About Schizophrenia}

As a caregiver, the person has to serve as both a support system for his/her family member and a liaison for their medical care. The caregivers usually juggle many different responsibilities with a steep learning curve which is simply not an easy task. The caregivers need a sound knowledge about the symptoms, treatments, prognosis, and other details so that they are better prepared to be effective in this role. However, according to Figure 2, it was found that $89 \%$ of respondent received no training on how to care for a patient while $60 \%$ did not even know the name of the illness of their relatives. 


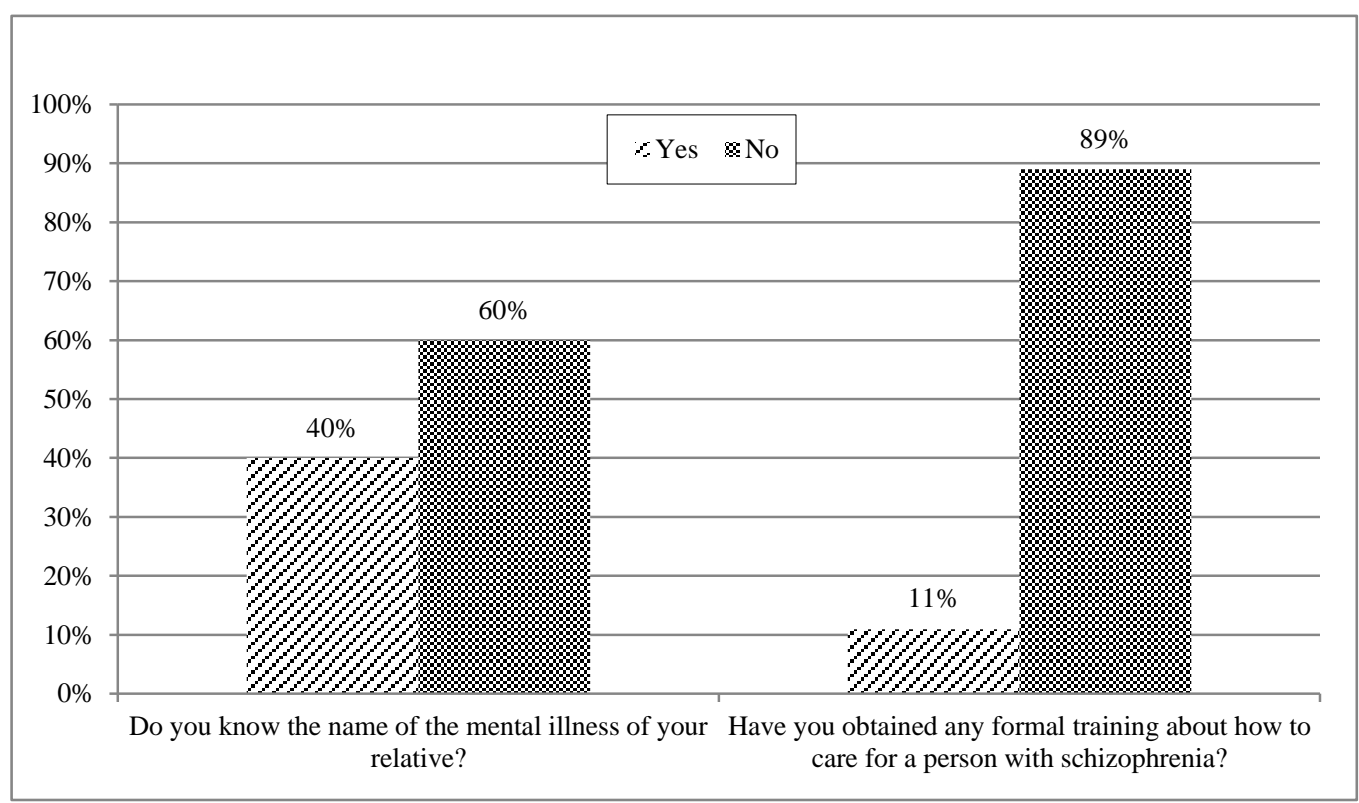

Figure 2. Carer's knowledge on schizophrenia

\subsection{Carer's Perception on Treatment of the Illness}

A person with schizophrenia is likely to be taking a prescription medication and receiving therapy to manage the symptoms. The caregivers are required to be prepared to assist in these tasks and they usually face several administrative difficulties. According to Figure 3, it can be seen that carers were facing problems with administration of medication. The majority (45\%) of respondent agreed with this statement "He /She takes medication everyday", 36 $\%$ agreed that "He/She sometimes stop taking medication when he/she feels better" and 33\% supported the statement that "Having to take regular medication is a burden for my family member with schizophrenia".

Moreover, Table 4 shows the results of a descriptive analysis of the different statements using a score scale from 1 (strongly disagree) to 5 (strongly agree). It was found that that the means of the resulting composite variables ranged from 2.92 to 3.31 on a scale of out of 5. The highest mean score was for the statement "He /She takes medication everyday" with a mean value 3.31, followed by the statement "When he/she feels better, he/she sometimes stop taking medicine" with a mean 3.02 and "Having to take regular medication is a burden for my family member with schizophrenia" with a mean 2.92 .

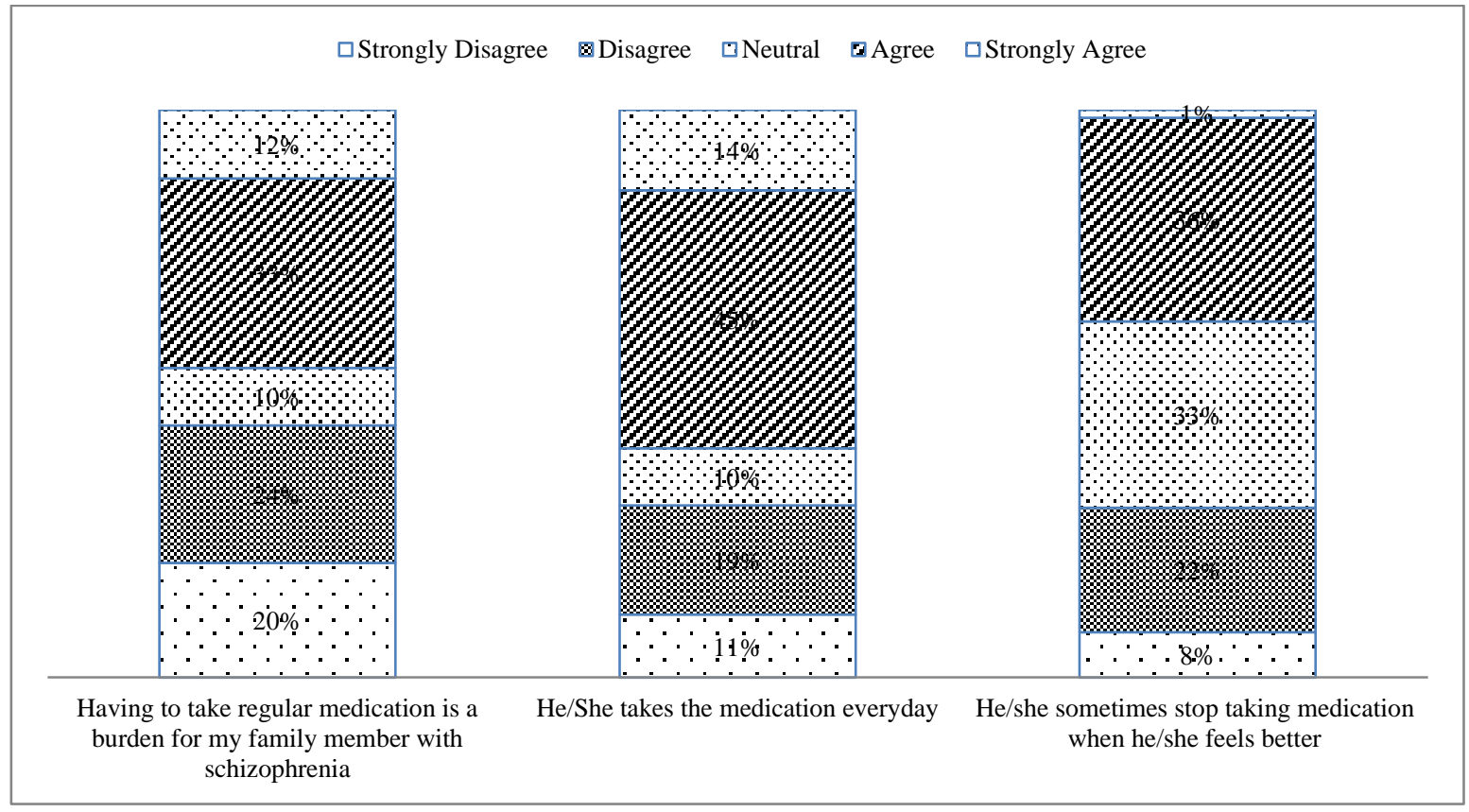

Figure 3. Perception of carers on treatment 
Table 4. Descriptive analysis (knowledge on schizophrenia and drug)

\begin{tabular}{ccccc}
\hline & Mean & $\begin{array}{c}\text { Standard } \\
\text { Deviation }\end{array}$ & t-value & p- value \\
\hline Having to take regular medication is a burden for my family & 2.9 & 1.4 & 12.5 & 0.013 \\
$\begin{array}{c}\text { member with schizophrenia } \\
\text { He /She takes medication everyday }\end{array}$ & 3.3 & 1.3 & 17.4 & 0.014 \\
When he/she feels better, he/she sometimes stop taking medicine & 3.0 & 1.0 & 18.8 & 0.023 \\
\hline
\end{tabular}

The observations made in Table 4 indicated that the respondent mostly agreed that their family member was not drug compliant. The average mean was 3.08 , therefore, it can be concluded that the response is mostly towards "agree" on the score scale. The p-values, for the three statements, were $<0.05$ which is highly significant for lack of knowledge among caregiver.

\subsection{Impact of the Caring Role on the Physical Health of the Carers}

A poor health of caregivers represents a risk factor for difficulties in managing the caregiving role with potential negative effects on the patient with schizophrenia. It was observed that the majority (96\%) of the respondents complained about feeling tired, $63 \%$ reported being short tempered and irritable, $61 \%$ complained of physical strain and stress, 57\% complained of feeling depressed, 56\% had a disturb sleep, 49\% were withdrawn from friends and activities. A low percentage (19\%) reported had to see a Doctor due to health problem.

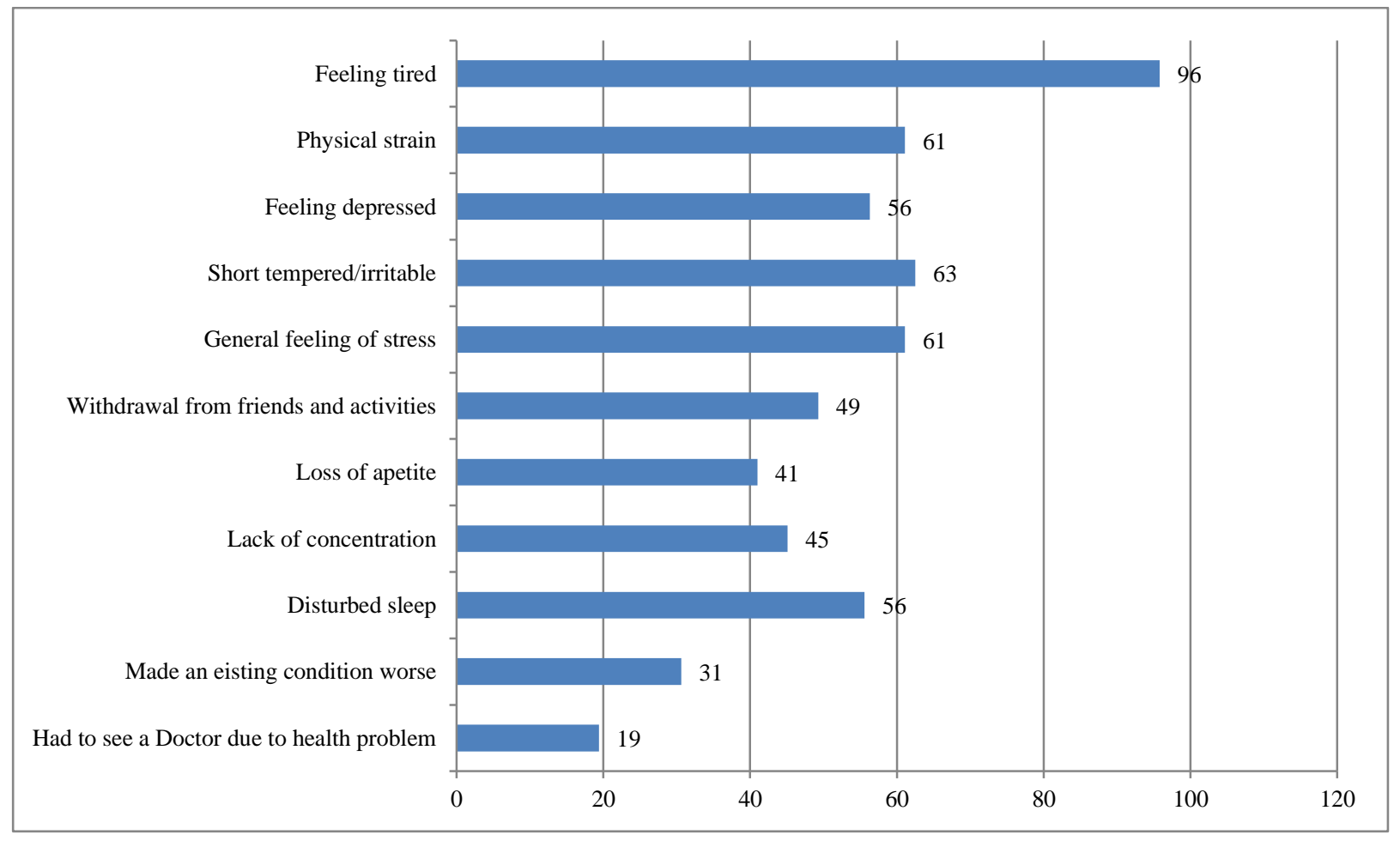

Figure 4. Caregiver reporting how their physical health was affected by their caring role

\subsection{Impact of the Caring Role on the Emotional Health of the Carers}

The respondent faced a high level of emotional distress. According to the study, a significant number of the respondent (82\%) agreed upon "I'm worried about my own safety when he/she becomes violent", 65\% respondents were always worried as stated "I'm worried that his/her schizophrenia might get worse" $49 \%$ often felt exhausted and cannot function properly while $64 \%$ very often felt sad about their close one. 


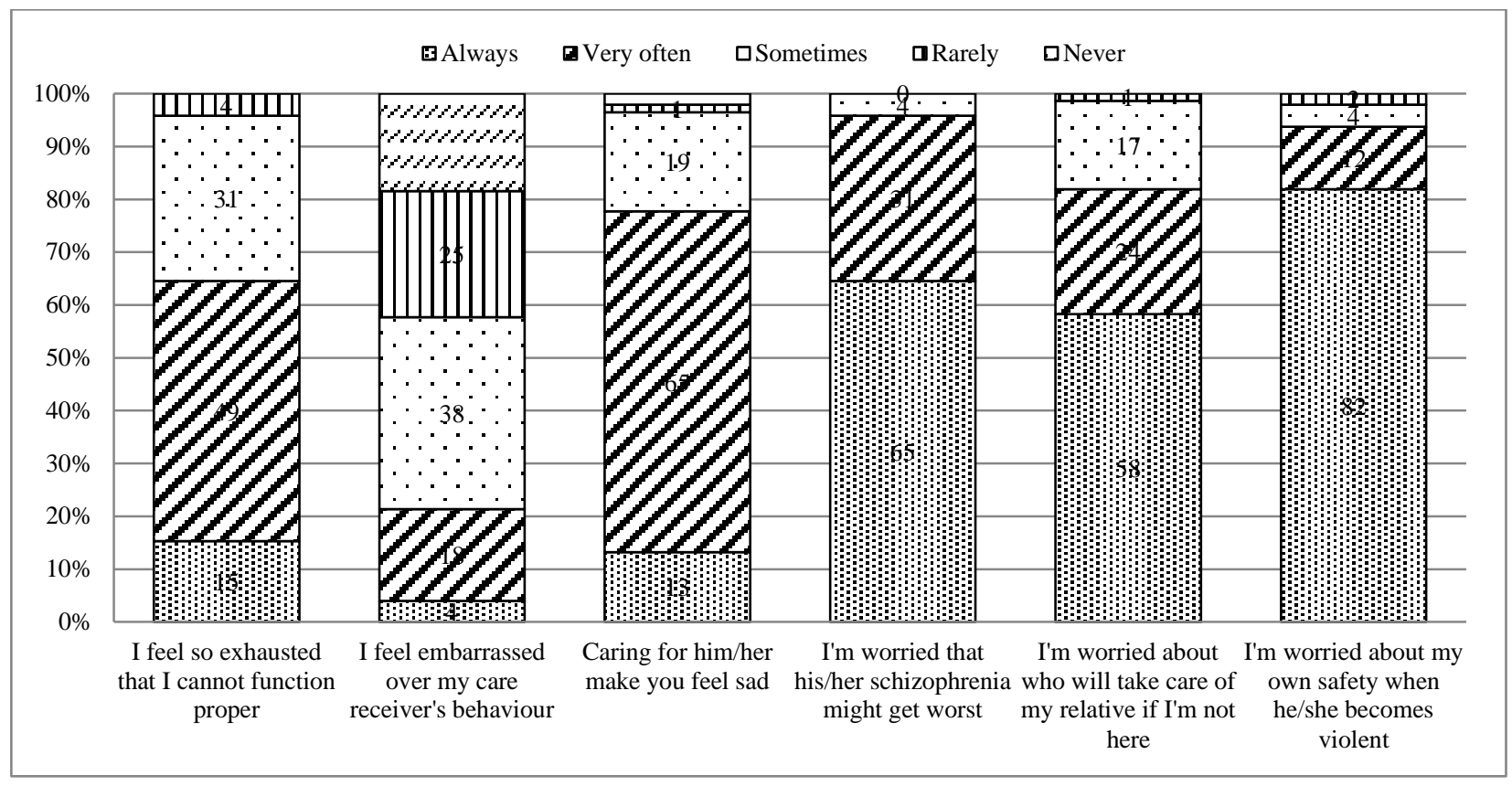

Figure 5. Carer's perspective on emotional health

A descriptive analysis (Table 5) showed that the mean value on a scale from 0 to 4 from never (score 0 ) to always (score 4) ranged from 1.6 for the statement "I feel embarrassed over my care receiver's behavior" to a mean of 2.6, followed by "Caring for him/her make you feel sad" with a mean of 2.9. The other statement "I am worried about who will take care of my relative if I'm not here" had a mean of 3.6 while "I'm worried about my own safety when he/she becomes violent" had a mean value of 3.9.

Table 5. Descriptive analysis of Emotional Wellbeing

\begin{tabular}{lcccc}
\hline \multicolumn{1}{c}{ Statements } & Mean & Standard Deviation & t-value & p-value \\
\hline I feel so exhausted that I cannot function properly & 2.6 & 0.6 & 20.5 & 0.001 \\
I feel embarrassed over my care receiver's behavior & 1.6 & 1.1 & 0.9 & 0.003 \\
Caring for him/her make you feel sad & 2.9 & 0.7 & 23.3 & 0.003 \\
I'm worried that his/her schizophrenia might get worse & 3.7 & 0.7 & 39.3 & 0.002 \\
I am worried about who will take care of my relative if I'm not here & 3.6 & 0.9 & 29.0 & 0.002 \\
I'm worried about my own safety when he/she becomes violent & 3.9 & 0.5 & 58.7 & 0.001 \\
\hline
\end{tabular}

The average mean value is 3.04, indicating respondents for the statement the five statements "I feel so exhausted that I cannot function properly", "Caring for him/her make you feel sad", "I'm worried that his/her schizophrenia might get worse", "I feel embarrassed over my care receiver's behavior", "I am worried about who will take care of my relative if I'm not here", I'm worried about my own safety when he/she becomes violent" have a p-value 0.00 are highly significant.

\subsection{Impact of the Caring Role on the Social Wellbeing of the Carers}

The support of friends and family plays an integral role in the treatment of schizophrenia. According to Figure 6, it can be observed that a high level of stigma (44\%) was perceived by carers for the statement "I avoid going to large social events with my relatives." Moreover, despite this stigmatization, $40 \%$ disagree that "it is better to hospitalize $\mathrm{him} / \mathrm{her}$ so that he/she is away" or 37\% disagree that "I'm worried that friends and neighbours will avoid me after they find out about my relative illness". Similarly, $28 \%$ disagree or neutral that "I feel that I'm drifting apart from my family and friends because of my caring role" 


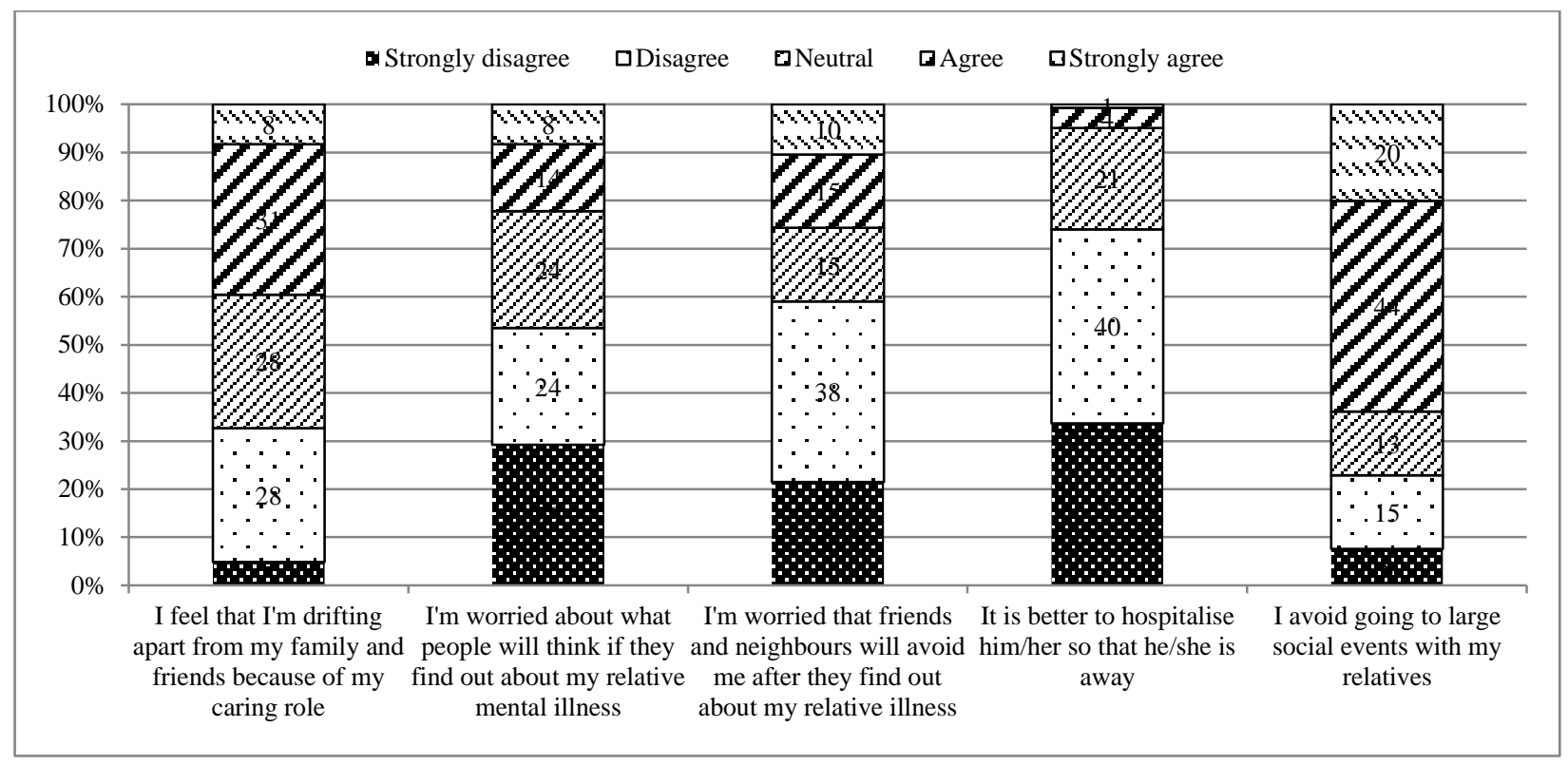

Figure 6. Perspective of social health and societal stigma perceived by the carers

A descriptive analysis (Table 6) showed that the mean value on a scale of five range from 1 to 5 from strongly disagree to strongly agree. Mean value ranging from 2.0 for the statement "It is better to hospitalize him/her so that he/she is away", to 2.5 for "I am worried about what people will think if they find out about my relative mental illness" to 2.6 for the statement "I am worried that friends and neighbours will avoid me after they find out about my relative illness". Interestingly, the mean value 3.10 for the statement "I feel I'm drifting apart my family and friends because of my caring role" was 3.1 and "I avoid going to large social events with my relative" had a mean value 3.5 meaning the respondents were most strongly agreeable with the statements.

Overall, the mean average was 2.7 indicating that there was a higher response towards strongly agree. The p-value 0.00 for the 5 statements was highly significant.

Table 6. Descriptive analysis for Social Health

\begin{tabular}{|c|c|c|c|c|}
\hline Statements & Mean & SD & t- value & p- value \\
\hline I feel I'm drifting apart my family and friends because of my caring role & 3.1 & 1.1 & 18.2 & 0.001 \\
\hline I am worried about what people will think if they find out about my relative mental illness & 2.5 & 1.3 & 9.2 & 0.003 \\
\hline I am worried that friends and neighbors will avoid me after they find out about my relative illness. & 2.6 & 1.3 & 10.0 & 0.003 \\
\hline It is better to hospitalize him/her so that he/she is away & 2.0 & 0.9 & 6.5 & 0.002 \\
\hline I avoid going to large social events with my relative & 3.5 & 1.2 & 20.2 & 0.002 \\
\hline
\end{tabular}

A Pearson Chi-Square test was conducted for hypothesis testing between increase in caregiving time and caregivers social wellbeing. The p-value was 0.015 (Table 7) indicating that the null hypothesis (increase in caregiving will not affect family caregivers' social wellbeing) was rejected and the $\mathrm{H}_{1}$ hypothesis (increase in caregiving will significantly affect family caregivers' social wellbeing) was accepted. There is therefore sufficient evidence that an increase in caregiving will significantly affect family caregivers' social wellbeing (Chi-Square $=12.331, \mathrm{p}$-value $=0.015$ and $\mathrm{df}$ was 4).

Table 7. Chi-Square Tests. (a: 4 cells $(\mathbf{4 0 . 0 \%})$ have expected count less than 5 . The minimum expected count is 0.35 )

\begin{tabular}{cccc}
\hline & Value & df & Asymptotic Significance (2-sided) \\
\hline Pearson Chi-Square & $12.331^{\mathrm{a}}$ & 4 & 0.015 \\
Likelihood Ratio & 13.325 & 4 & 0.010 \\
Linear-by-Linear Association & 5.727 & 1 & 0.017 \\
No of Valid Cases & 144 & & \\
\hline
\end{tabular}




\subsection{Financial Burden Faced by the Carers during the Last 12 Months}

In this study, financial burden is one of the major challenges faced by caregivers as shown in Figure 7 below. Majority of the caregivers $(62.5 \%)$ complained of facing a lot of financial difficulties during the last 12 months. Only $11.1 \%$ reported not feeling any financial constraints at all.

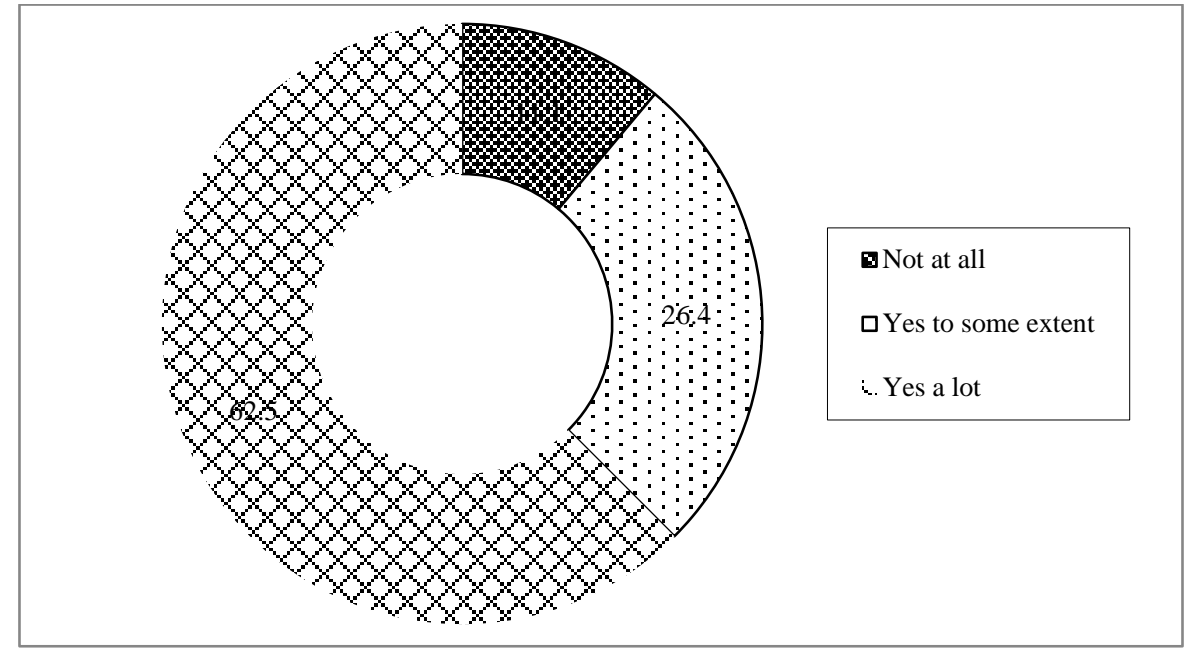

Figure 7. Financial difficulties faced by caregiver during the last 12 months

The financial burden was felt more by the female caregivers $(67 \%)$ than the male. About $44 \%$ of the male even reported "Not at all" regarding any financial constraints with the patient. This prompted us to conclude that carers were not getting enough financial support or family support. In certain cases the social aid that they were receiving was not enough as evidenced by Figure below.

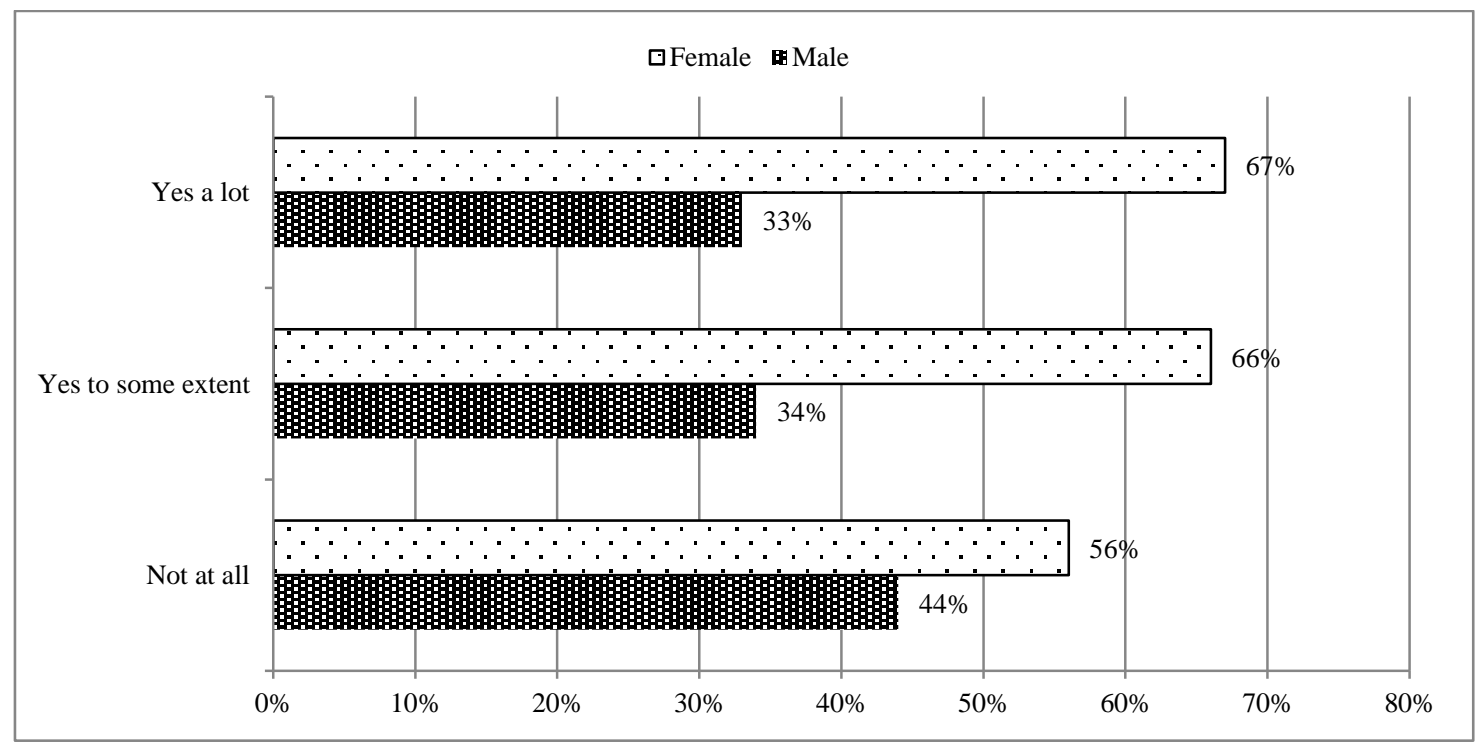

Figure 8. Financial difficulties faced by caregiver according to gender

\section{Discussion}

Globally, an estimated 21 million people are living with schizophrenia and this number will continue to rise with population ageing and growth [15]. Caregivers of patients with schizophrenia are under the burden of continuous and difficult processes [16]. Determination of the factors related to caregiver burden in schizophrenia may help to find strategies to lighten the impact of the burden. This study aimed at investigating the factors associated with caregiver burden among relatives of patients with schizophrenia in a multicultural society of Mauritius.

It has been shown in previous studies on caregiver burden and the World Federation of Mental Health that mostly females assume the care of patients with schizophrenia [16]. The socio-demographic characteristics of the caregivers in this study have shown that the majority of carers were female, including mother, daughter, sister, aunt or partner. Similarly, a studycarried out in the United Kingdom, revealed about 58\% of the caregivers were women [17] and in 
another study carried out in Asia found out about $70 \%$ of family caregivers were females [18]. However, these observations are in contrast with research carried by Poreddi et al. [19] where 64\% of the carers were male and that of Zahid and Ohaeri [20], who reported a male composition of $66.1 \%$ among the carers. Women's work roles are viewed as being centred in the home and may reflect a greater sense of family obligation among them [21]. This information shows that the female caregivers should be empowered while ways of engaging more males in assuming this stressful duty should be explored.

As it was previously reported that older caregivers may be particularly vulnerable because caregiving demands may tax their health and physical abilities and compromise the immune response systems [22], it was found that majority of the caregivers in Mauritius were more than 55 years old and were providing care for more than 16 years. This age group is quite high as compared to Shibre et al. [23] who found carers with the age of 35 years old in Ethiopia and Yusuf et al. [24] with a mean age of 45 years old in Nigeria. Studies conducted in Asian countries show that caregiver burden increases with advancing age of the caregiver, whereas it decreases with age in Mexico and America [25]. Moreover, in a previous study by Gülseren et al. [26] with 237 caregivers, it was found that the duration of the illness had positive associations with caregiver burden. The length of time the caregivers spent, in giving care to patient plays a crucial role in the depth of the burden of what the caregiver experiences. However, we observed in this study that most $(59 \%)$ of the respondents spent more than 40 hours a week caring for their relatives with schizophrenia which is in in comparison with the 22.5 hours in the European study conducted by Flyckt et al. [27]. This shows that cultural factors may play a role in determining age factor and duration for caregiving roles of schizophrenia patients.

Level of education of the caregivers is an important factor to be considered in this study. Although there are previous studies showing that as the education level of the family member increases, caregiver burden decreases, some recent studies have also produced results contrary to this study [28]. It is interesting to note that a high proportion $(47 \%)$ of the caregivers studied up to secondary level and some even completed tertiary studies (7\%). Yazici et al. [16] reported in a study conducted in Turkey that as the education level of the caregiver increased, caregiver burden decreased and the authors suggested that younger and better educated persons would feel less caregiver burden when providing care to patients with schizophrenia.

According to a previous study by Gupta et al. [29], schizophrenia caregivers commonly experience physical health impacts including stress-related comorbidities including insomnia, pain, headaches, heartburn, anxiety and depression. Similarly this study showed that $95.8 \%$ respondent complained of feeling tired while $62.5 \%$ complained of short tempered and irritability. To further complicate matters, $80.6 \%$ respondents did not visit a doctor even though they were not enjoying good health. It was previously reported that nearly three quarters (72\%) of caregivers reported that they had not gone to the doctor as often as they should, and more than half (55\%) had missed doctor's appointments [30].

It was also found that a high level of stigma (44\%) was perceived by carers for the statement "I avoid going to large social events with my relatives." This is in line with the study of Fernando et al. [31] where it was reported that carers observed a high level of stigma. Leong et al. [30] reported that caregivers often lack social contact and support and experience feelings of social isolation. To alleviate the situation few studies have proposed the importance and usefulness of psychoeducation programs [32] and psychoeducation groups for families which have become the core of most rehabilitation programs [33]. Serrano et al. [34] highlighted that one psychosocial intervention significantly increased the number of support persons for caregivers, their satisfaction with their support network, and the assistance they received with caregiving.

Harmanci and Cetinkaya-Duman [35] stated that the caregivers of patients with schizophrenia have high risk for their mental health problems, their burdens affect their mental health status, and mental health problems also increase if the burden of care increases. In the same line, it was observed in this study that the caregivers faced a high level of emotional distress. 81.9\% agreed upon "I'm worried about my own safety when he/she becomes violent. The caregivers caring for their family member with mental illness feel stressed, anxious, worry, uncomfortable, and low, because the illness has a tendency to become chronic and is awfully demanding. In the long run, this may result in burnout and emotional exhaustion. The caregivers feel isolated from the society, both due to restriction of their social and leisure activities, as well as the social discrimination and stigma attached to the mental illnesses. Some caregivers may need to look after more than one patient in the family. Leong et al. [30] suggested that caregivers tend to sacrifice their leisure pursuits and hobbies, to restrict time with friends and family, and to give up or reduce employment. As proposed by Caqueo-Urizar et al. [28], working outside the home, generating incomes and maintaining other activities aside from patient care can protect caregivers's mental health.

Financial burden is one of the major challenges faced by caregivers. It can be seen that a large portion of the caregivers complained of facing a lot of financial difficulties during the last 12 months. This finding is similar to that reported by several authors in United States of America [36], Ghana [37] and in other rural African settings such as in Ethiopia [38] and Nigeria [39]. The female carers faced financial problem more than the male gender. In Mauritius, the carers were not getting enough financial support or family support. In certain cases the social aid that they received was not enough. This is in line with study conducted by Ganguly et al. [40] where the authors observed that caregivers 
commonly experience financial difficulties when having to care for patient with schizophrenia. In most cases the caregiver is the bread winner and at the same time has to attend to the family care giver and this can put a barrier between and family commitment. Due to patient destructive behaviour, caregivers need to do extra expenses as they must replace damaged or destroyed property [41].

\section{Conclusion}

To conclude, an increase in care giving role resulted in poor physical health, poor emotional well-being, poor social health and increase in financial worry. Parent caregivers for persons with schizophrenia experience tremendous difficulty navigating the health care system and they often prioritize their caregiving responsibilities above their own health and well-being. The study describes the sociodemographic structure of the Mauritian caregivers of schizophrenia and how caregivers' physical health, emotional health, social health and financial status were affected due to caregiving responsibilities in the small island development state Mauritius. Like many studies, this survey suffers from few limitations. Despite the decentralisation process, this study was carried out in only the main mental healthcare centre, which remains the specialized hospital in the provision of mental health services in Mauritius. Hence, the results cannot be generalised to the population at large. The sample size was relatively small and thus a multi-centered study is recommended. Nevertheless, the finding helps to encourage the health care providers to understand, acknowledge, and address caregivers' needs, to advocate for a less fragmented mental health care system, and to support parent caregivers to be empowered and satisfied in their role. It is recommended to educate and provide resources for caregivers of mental illness patients, about issues of stress and caregiver health. Future directions include the need for longitudinal studies to understand the burden and quality of life in caregivers over a period of time and to implement effective intervention strategies to reduce the burden and improve the quality of life among caregivers.

\section{Acknowledgements}

We express our heartfelt thanks to the Medical Superintendent of the BSMHC for approval to conduct the study on relatives of patients from the centre, the Ward Manager, the nurses and all other staff members for their generous contribution and support in data collection of the project.

\section{Declaration of Competing Interest}

The authors declare that they have no known competing financial interests or personal relationships that could have appeared to influence the work reported in this paper.

\section{Ethical Approval}

All procedures performed in studies involving human participants were in accordance with the ethical standards of the National Ethics Committee of Mauritius and with the 1964 Helsinki declaration and its later amendments or comparable ethical standards.

\section{References}

[1] Vos, T., Abajobir, A. A., Abate, K. H., Abbafati, C., Abbas, K. M., Abd-Allah, F., ... Abera, S. F. (2017). Global, regional, and national incidence, prevalence, and years lived with disability for 328 diseases and injuries for 195 countries, 1990-2016: a systematic analysis for the Global Burden of Disease Study 2016. The Lancet, 390(10100), 1211-1259. doi:10.1016/s01406736(17)32154-2.

[2] Harvey, P. D., Raykov, T., Twamley, E. W., Vella, L., Heaton, R. K., \& Patterson, T. L. (2011). Validating the Measurement of Real-World Functional Outcomes: Phase I Results of the VALERO Study. American Journal of Psychiatry, 168(11), 11951201. doi:10.1176/appi.ajp.2011.10121723.

[3] Harvey, P. D. (2010). Cognitive Functioning and Disability in Schizophrenia. Current Directions in Psychological Science, 19(4), 249-254. doi:10.1177/0963721410378033.

[4] Rössler, W., Joachim Salize, H., van Os, J., \& Riecher-Rössler, A. (2005). Size of burden of schizophrenia and psychotic disorders. European Neuropsychopharmacology, 15(4), 399-409. doi:10.1016/j.euroneuro.2005.04.009.

[5] American Psychiatric Association. (2013). Diagnostic and Statistical Manual of Mental Disorders. Fifth Edition. Arlington, VA. doi:10.1176/appi.books.9780890425596.

[6] Herzog, E. A. (2014). Schizophrenia and schizophrenia spectrum disorders, in Halter, M.J. (ed) Varcarolis' foundations of psychiatric mental health nursing (7th ed.), 200-224. St. Louis, MO: Elsevier.

[7] Levene, J. E., Lancee, W. J., \& Seeman, M. V. (1996). The perceived family burden scale: measurement and validation. Schizophrenia Research, 22(2), 151-157. doi:10.1016/s0920-9964(96)00071-0. 
[8] Ramphul, K. (2018). Mauritius needs to address mental illness, starting in schools. The Lancet Psychiatry, 5(10), $786-787$. doi:10.1016/s2215-0366(18)30304-3.

[9] Park, B., Kim, S., Shin, J., Sanson-Fisher, R., Shin, D., Cho, J., \& Park, J. (2013). Prevalence and predictors of anxiety and depression among family caregivers of cancer patients: a nationwide survey of patient-family caregiver dyads in Korea. Supportive Care in Cancer, 21(10), 2799-2807. doi:10.1007/s00520-013-1852-1.

[10] Miller, F., Dworkin, J., Ward, M., \& Barone, D. (1990). A preliminary study of unresolved grief in families of seriously mentally ill patients. Hospital \& Community Psychiatry, 41 (12), 1321-1325. doi:10.1176/ps.41.12.1321.

[11] Wahl, O., \& Harman, C. (1989). Family views of stigma. Schizophrenia Bulletin, 15(1), 131-139. doi:10.1093/schbul/15.1.131.

[12] Schene, A., Tessler, R., \& Gamache, G. (1994). Instruments measuring family or caregiver burden in severe mental illness. Social Psychiatry and Psychiatric Epidemiology, 29(5), 228-240. doi:10.1007/BF00796381.

[13] Bevans, M., \& Sternberg, E. (2012). Caregiving burden, stress, and health effects among family caregivers of adult cancer patients, Journal of the American Medical Association, 307(4), 398-403. doi:10.1001/jama.2012.29.

[14] Lippi, G. (2016). Schizophrenia in a member of the family: Burden, expressed emotion and addressing the needs of the whole family. South African Journal of Psychiatry, 22 (1), 922. doi:10.4102/sajpsychiatry.v22i1.922.

[15] Charlson, F. J., Ferrari, A. J., Santomauro, D. F., Diminic, S., Stockings, E., Scott, J. G., McGrath , J. J., \& Whiteford, H. A. (2018). Global epidemiology and burden of schizophrenia: findings from the global burden of disease study 2016. Schizophrenia Bulletin, 44 (6), 1195-1203. doi:10.1093/schbul/sby058.

[16] Yazici, E., Karabulut, U., Yildiz, M., Tekeş, S.B., İnan, E., Çakir, U., Boşgelmez, S., \& Turgut, C. (2016). Burden on Caregivers of Patients with Schizophrenia and Related Factors. Archieves of Neuropsychiatry, 53(2), 96-101. doi:10.5152/npa.2015.9963.

[17] Nolan, M. (2001). Supporting family carers in the UK: overview of issues and challenges. British Journal of Nursing, 10(9), 608-613. doi:10.12968/bjon.2001.10.9.9380.

[18] Chan, S., Yip, B., Tso, S., Cheng, B., \& Tam, W. (2009). Evaluation of a psychoeducation program for Chinese clients with schizophrenia and their family caregivers. Patient Education and Counseling, 75(1), 67-76. doi:10.1016/j.pec.2008.08.028.

[19] Poreddi, V., Ramachandra., Reddemma, K., \& Math, S. B. (2013). People with mental illness and human rights: A developing countries perspective. Indian Journal of Psychiatry, 55(2), 117-124. doi:10.4103/0019-5545.111447.

[20] Zahid, M., \& Ohaeri, J. (2010). Relationship of family caregiver burden with quality of care and psychopathology in a sample of Arab subjects with schizophrenia. BioMed Central Psychiatry, 10, 71. doi:10.1186/1471-244X-10-71.

[21] Gallicchio, L., Siddiqi, N., Langenberg, P., \& Baumgarten, M. (2002). Gender differences in burden and depression among informal caregivers of demented elders in the community. International Journal of Geriatric Psychiatry, 17(2), $154-163$. doi:10.1002/gps.538.

[22] Navaie-Waliser, M., Feldman, P.H., Gould, D.A., Levine, C., Kuerbis, A.N., \& Donelan, K. (2002). When the caregiver needs care: the plight of vulnerable caregivers. American Journal of Public Health, 92 (3), 409-413. doi:10.2105/ajph.92.3.409.

[23] Shibre, T., Negash, A., Kullgren, G., Kebede, D., Alem, A., Fekadu, A., Fekadu, D., Medhin, G. and Jacobsson, L. (2001). Perception of stigma among family members of individuals with schizophrenia and major affective disorders in rural Ethiopia. Social Psychiatry and Psychiatric Epidemiology, 36(6), 299-303. doi:10.1007/s001270170048.

[24] Yusuf, A., Nuhu, F., \& Akinbiyi, A. (2009). Caregiver burden among relatives of patients with schizophrenia in Katsina, Nigeria. South African Journal of Psychiatry, 15(2), 43-47. doi:10.4102/sajpsychiatry.v15i2.187.

[25] Chan, S.W. (2011). Global perspective of burden of family caregivers for persons with schizophrenia. Archieves of Psychiatric Nursing, 25 (5), 339-349. doi:10.1016/j.apnu.2011.03.008.

[26] Gülseren, L., Cam, B., Karakoç, B., Yiğit, T., Danac1, A.E., Cubukçuoğlu, Z., Taş, C., Gülseren, S., \& Mete, L. (2010). The perceived burden of care and its correlates in schiาzophrenia. Turk Psikiyatri Dergisi, 21 (3), 203-212.

[27] Flyckt, L., Löthman, A., Jörgensen, L., Rylander, A., \& Koernig, T. (2011). Burden of informal care giving to patients with psychoses: A descriptive and methodological study. International Journal of Social Psychiatry, 59(2), 137-146. doi:10.1177/0020764011427239.

[28] Caqueo-Urizar, A., \& Gutierrez-Maldonado, J. (200). Burden of care in families of paרtients with schizophrenia. Quality of Life Research, 15(4), 719-724. doi:10.1007/s11136-005-4629-2. 
[29] Gupta, S., Isherwood, G,, Jones, K., \& Van Impe, K. (2015). Assessing health status in informal schizophrenia caregivers compared with health status in non-caregivers and caregivers of other conditions. BMC Psychiatry, $15,162$. doi:10.1186/s12888-015-0547-1.

[30] Leong, J., Madjar, I., \& Fiveash, B. (2010). Needs of family carers of elderly people with dementia living in the community. Australasian Journal on Ageing, 20(3), 133-138. doi:10.1111/j.1741-6612.2001.tb01775.x.

[31] Fernando, S., Deane, F., McLeod., H., \& Davis, E. (2017). A carer burden and stigma in schizophrenia and affective disorders: Experiences from Sri Lanka. Asian Journal of Psychiatry, 26, 77-81. doi:10.1016/j.ajp.2017.01.023.

[32] Tanrıverdi, D., \& Ekinci, M. (2012). The effect psychoeducation intervention has on the caregiving burden of caregivers for schizophrenic patients in Turkey. International Journal of Nursing Practice, 18(3), 281-288. doi:10.1111/j.1440172X.2012.02033.x.

[33] Sherman, M. (2003). Rehab Rounds: The Support and Family Education (SAFE) Program: Mental Health Facts for Families. Psychiatric Services, 54(1), 35-37. doi:10.1176/appi.ps.54.1.35.

[34] Serrano-Aguilar, P., Lopez-Bastida, J., \& Yanes-Lopez, V. (2006). Impact on Health-Related Quality of Life and Perceived Burden of Informal Caregivers of Individuals with Alzheimer's Disease. Neuroepidemiology, 27(3), 136-142. doi: $10.1159 / 000095760$.

[35] Harmanc1, P., Cetinkaya-Duman, Z. (2016). Investigating relationship between burden of caregivers of patients with schizophrenia and mental health conditions. Journal of Psychiatric Nursing, 7(2), 82-86. doi:10.5505/phd.2016.15870.

[36] Covinsky, K. (1994). The impact of serious illness on patients' families. SUPPORT Investigators. Study to understand prognoses and preferences for outcomes and risks of treatment. The Journal of the American Medical Association, 272(23), 1839-1844. doi:10.1001/jama.272.23.1839.

[37] Quinn, N. (2007). Beliefs and community responses to mental illness in Ghana: The experiences of family carers. International Journal of Social Psychiatry, 53(2), 175-188. doi:10.1177/0020764006074527.

[38] Shibre, T., Kebede, D., Alem, A., Negash, A., Deyassa, N., Fekadu, A., Fekadu, D., Jacobsson, L. \& Kullgren, G. (2003). Schizophrenia: illness impact on family members in a traditional society - rural Ethiopia. Social Psychiatry and Psychiatric Epidemiology, 38(1), 27-34. doi:10.1007/s00127-003-0594-7.

[39] Igberase, O. O., Morakinya, O., Lawani, A. O., James, B. O., \& Omoaregba, J. O. (2010). Burden of care among relatives of patients with schizophrenia in Midwestern Nigeria. International Journal of Social Psychiatry 58(2), $131-137$. doi:10.1007/s00127-003-0594-7.

[40] Ganguly, K. K., Chadda, R. K., \& Singh, T. B. (2010). Caregiver Burden and Coping in Schizophrenia and Bipolar Disorder: A Qualitative Study. American Journal of Psychiatric Rehabilitation, 13(2), 126-142. doi:10.1080/15487761003757009.

[41] Gutiérrez-Maldonado, J., Caqueo-Urízar, A., \& Kavanagh, D. (2005). Burden of care and general health in families of patients with schizophrenia. Social Psychiatry and Psychiatric Epidemiology, 40(11), 899-904. doi:10.1007/s00127-005-0963-5. 